\title{
Literatura y estética cotidiana: hacia la \\ formulación de una hipótesis abductiva*
}

\section{//Literature and everyday aesthetics \\ Towards an abductive reasoning}

Investigaciones $\quad \begin{aligned} & \text { de Educación, N. } 63 . \\ & \text { Segundo semestre de 2012, }\end{aligned}$

//Literatura e estética cotidiana: para a
formulação de uma hipótese abdutora

Horacio Pérez Henao**

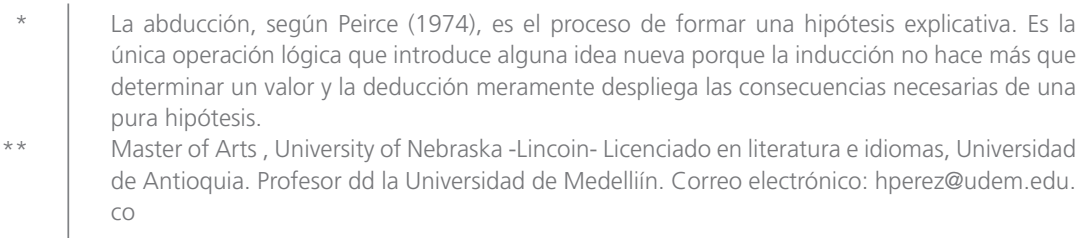

\section{Resumen}

El presente artículo muestra el camino recorrido para la formulación de una hipótesis abductiva en relación con la estética cotidiana y el estudio de la literatura en la educación superior. Partiendo de la experiencia docente del autor, el texto da cuenta de un proceder metodológico abductivo que apunta hacia un acto de creación. Categorías como hecho sorprendente, ícono, enigma, indicio, sospecha y conjetura conducen a la enunciación final de la hipótesis en forma de pregunta. Dicha pregunta constituye uno de los momentos iniciales de un proyecto de investigación en proceso de formulación, que busca fundamentar la estética cotidiana a partir de la literatura como principio para la educación superior.

\section{Abstract}

Based on author's teaching experience, this paper reports a process carried out to establish an abductive hypothesis regarding everyday aesthetics and literature studies in higher education. Categories such as surprising fact, icon, enigma, hint, suspicion, and conjecture lead to a definitive hypothesis as a question. Such a question is one of the starting points of a research project under formulation, which seeks to propose a principle for higher education taking literature as support of everyday aesthetics.

\section{Resumo}

O presente artigo mostra o caminho percorrido para a formulação de uma hipótese abdutora em relação com a estética cotidiana e o estudo da literatura na educação superior. Partindo da experiência docente do autor, o texto dá conta de um proceder metodológico abdutor que aponta para um ato de criação. Categorias como fato surpreendente, ícone, enigma, indício, suspeita e conjectura conduzem à enunciação final da hipótese na forma de pergunta. A referida pergunta constitui um dos momentos iniciais de um projeto de investigação em processo de formulação, que busca fundamentar a estética cotidiana a partir da literatura como princípio para a educação superior.

\section{Palabras Clave}

Estética cotidiana, estudios literarios, abducción.

\section{Keywords}

Everyday aesthetics, literary studies, abduction.

\section{Palavras chave}

Estética cotidiana, estudos literários, abdução. 


\section{El hecho sorprendente: ¿por qué la sorpresa nos lanza al mundo de la duda?}

El estudio de la literatura en la institución académica universitaria ha estado marcado por un interés fundamentalmente instrumental: la profesionalización de la mirada sobre el texto literario. Tanto en los ámbitos de los programas de pregrado como de posgrado, la literatura se ha abordado -tradicionalmente- como un objeto comparable a aquellos de las ciencias exactas. Es decir, el texto literario adopta un cariz casi científico, o al menos racionalista, como consecuencia de las humanidades "refugiadas en unos especialistas casi siempre inaccesibles en sus jergas herméticas y una erudición asfixiante, cuando no en teorías delirantes" (Vargas Llosa, 2012, p. 22).

En este marco, justamente, surge lo que aquí -con base en los planteamientos de Peirce (1970)- denominamos hecho sorprendente. En el desempeño como docente de literatura en la Facultad de Comunicación de la Universidad de Medellín, imparto algunos cursos cuyos contenidos, objetivos y metodologías trazan el estudio de la literatura desde teorías estéticas y literarias tradicionales, enfocadas predominantemente en la objetualidad del texto literario, a saber: el formalismo ruso, el estructuralismo, el posestructuralismo, la semiótica, el marxismo, la estética de la recepción, entre otras. Los microcurrículos ${ }^{2}$ de tales cursos se estructuran alrededor del desarrollo de la facultad estética del estudiante; pero sus pretensiones, más que estéticas, son racionalistas ${ }^{3}$. Desde ellos la literatura parece conducir al estudiante a un tipo de conocimiento medible, demostrable, comparable o explicable, tal como sucede (a manera de ilustración) en La elegancia del erizo, la novela de Barbery (2010). En ese relato, Palo$\mathrm{ma}$, una de las narradoras, desprecia a su instructora de literatura por transmitir en la clase la idea de que el estudio de los textos se reduce a la habilidad para identificar al narrador, las peripecias o los personajes, nunca para expresar el placer, los sentimientos o afectos y efectos que despierta el libro en los alumnos ( $p$. 171). René, otra de las narradoras, cuestiona el hecho de que la

1 Para Peirce (1970), los hechos sorprendentes son "hechos muy diferentes a todo lo observado" (p. 79). Es decir, son hechos que "rompen con una suerte de equilibrio cognitivo con el medio y con el corpus de conocimiento existente" (Espejo, 2008), llevándonos a un estado dubitativo.

2 El microcurrículo es el programa particular correspondiente a cada asignatura de un pénsum académico. En él se incluyen: problema de formación, propósito de formación objeto de estudio, objetivos, conceptos, métodos, temas, estrategias didácticas, estrategias evaluativas y bibliografía.

3 Al mencionar lo racionalista, nos referimos a la búsqueda de un conocimiento basado solo y exclusivamente en la razón. 
"Universidad se empeñe en enseñar los principios narrativos a golpe de Propp, Greimas u otros castigos..." (p. 78). De manera clara, las narradoras personaje intuyen que la literatura está a su alcance para ampliar el horizonte de sus estrechas vidas, y no para demostrar ante un profesor el dominio de enmarañadas teorías. Las preocupaciones de esos personajes de ficción (que, de algún modo, son también las de Barbery, profesora universitaria) son similares a las nuestras. ¿Por qué orientar el estudio de la literatura hacia un avezado conceptualismo? ¿Por qué no acceder a lo literario con el fin de ampliar el horizonte de vida?

Es sabido que las perspectivas tradicionales de los estudios literarios han marcado la dinámica de las teorías estéticas no solo alrededor de la literatura, sino también del arte en general. En los siglos XX y $X X I$, la discusión sobre las particularidades del arte continúa despertando interés. Sin embargo, mientras las teorías persisten en legitimar sus posiciones en el campo literario ${ }^{4}$, la pregunta por el lector y su cotidianidad se manda a la habitación del rebujo. ¿Cómo hacer para que el núcleo de comprensión e interpretación de un texto literario sea la vida cotidiana? ¿Es posible pensar que la literatura ensancharía el horizonte de vida en tanto ofrece al lector elementos para estetizar la cotidianidad?

4 Pierre Bourdieu hace referencia a las categorías de campo y posiciones en Las reglas del arte: génesis y estructura del campo literario (2005).
Uno de los teóricos más reconocidos, Todorov (2009), da una luz a estos interrogantes, cuando declara que la literatura le ha ayudado a vivir (p. 17). Otrora divulgador del formalismo ruso ${ }^{5}$, el autor declara que "la literatura, más densa y más elocuente que la vida cotidiana, pero no radicalmente diferente, amplía nuestro universo, nos invita a imaginar otras maneras de concebirlo y de organizarlo" (ibíd.). En su declaración, el lingüista habla de sentimientos y emociones, no de conocimientos eruditos ni elaboraciones abstractas sobre el texto literario; por el contrario, enfatiza el aspecto sensible involucrado en la lectura de un poema o ficción: "[La literatura] nos ofrece sensaciones insustituibles que hacen que el mundo real tenga más sentido y sea más hermoso" (p. 17). De manera similar, Bruner (2003) expresa que: "narrative, including fictional narrative, gives shape to things in the real world and often bestows on them a little to reality" (p. 8). Por consiguiente, la narrativa literaria -por ejemplo- no se agotaría en los límites del texto y su carácter lingüístico; ella da forma a las cosas del mundo. En la misma vía, Nussbaum (1997) se pregunta qué sentido de la vida encarna la imaginación literaria; cuál es el sentido de la vida que anima al texto en su conjunto (p. 28). Su propósito es mostrar que la imaginación literaria puede servir en la vida pública: "Guiar a los jueces en sus juicios, a

5 Prueba de ello es su texto Teoría de la literatura de los formalistas rusos (1970). 
los legisladores en su labor legislativa, a los políticos cuando midan la calidad de vida de gentes cercanas y lejanas" (p. 27).Es decir, la literatura vinculada al mundo de la vida.

El hecho sorprendente, entonces, es que el estudio de la literatura en la institución académica universitaria deja por fuera la relación lector-literatura y literatura-vida cotidiana al dar prelación a teorías que asumen la literatura como objeto de un conocimiento racionalista. ¿Es este el camino para desarrollar la facultad estética del estudiante?

\section{Los íconos‘: ¿cuál es locus de la estética en la literatura?}

El Proyecto Educativo Institucional (PEI) de la Universidad de Medellín, el Proyecto Educativo del Programa (PEP) de la carrera de Comunicación y Lenguajes Audiovisuales y los microcurrículos de las asignaturas de literatura funcionan -para nuestros propósitos metodológicos- como íconos, en cuanto semejanzas materializadas de la concepción del estudio de la literatura o de la concreción de las motivaciones institucionales alrededor del estudio de la estética y la literatura. Ahora bien, ¿qué fundamenta la inclusión del estudio de la estética y la literatura en la Universidad de Medellín? Miremos.

El concepto de estética aparece en el numeral seis de los fines y principios institucionales declarados por la Universidad en el $\mathrm{PEI}^{7}$. La categoría es referida a través de la palabra artístico:

Fomentar el conocimiento y defensa de los valores de la nacionalidad, la expansión de las áreas de creación y goce de la cultura, la incorporación integral de las personas a los beneficios del desarrollo científico, cultural, tecnológico y artístico que de todo ello se derive, y la protección y el aprovechamiento de los recursos naturales para aplicarlos a la satisfacción de las necesidades humanas (p. 57).

Por su parte, lo estético es enunciado en el capítulo de los principios así:

6 El ícono, según Peirce (1988), es "el único modo de comunicar directamente una idea" (p. 145) y, como tal, "es un tipo de signo que funciona en virtud de la semejanza existente entre la representación sígnica y lo representado" (González, 2012b, p. 5).

7 Proyecto Educativo Institucional Universidad de Medellín, 2012. p. 57. Recuperado de http://www.udem.edu.co/UDEM/Institucional/PEI/ 
El diseño, la revisión y el ajuste para hacer los currículos flexibles, con el fin de propiciar la interdisciplinariedad, como requisitos para la formación de profesionales competentes, con criterios éticos y estéticos $y$ una alta dosis de $\mathrm{s} \mathrm{o}$ lidaridad y compromiso con el crecimiento de la sociedad (p. 7).

En el caso del PEP, el interés por lo estético se manifiesta en el capítulo "Ensayo de fundamentación o acerca de la relación del programa con el PEI":

El comunicador en lenguajes audiovisuales será un trabajador de la cultura en las sociedades del conocimiento y tendrá como objeto de estudio el proceso de transformación de historias reales o imaginarias en lenguaje audiovisual. Para abordar este estudio, el comunicador tendrá que desarrollar esencialmente las competencias de la percepción, la sensibilidad, el análisis, la interpretación, la creación, la composición, la producción, la realización, la gestión, la comunicación, la investigación y el manejo de las nuevas tecnologías (p. 13).
En el mismo capítulo se definen las competencias que el programa de Comunicación y Lenguajes Audiovisuales busca desarrollar en el estudiante, a saber: argumentativa, comunicativa, estética, socio-afectiva, investigativa, tecnológica y narrativa. Justamente, la competencia estética "se entiende como la capacidad necesaria para apreciar, tanto el mundo natural como las creaciones humanas, desde la sensibilidad, con criterios valorativos claros y coherentes; así como para producir obras con sensibilidad artística" (p. 14). La competencia narrativa, por su parte, se define como la "capacidad para estructurar relatos coherentes a partir de la articulación de imágenes, palabras y sonidos, a fin de generar mensajes, sensaciones y sentimientos en los espectadores de estos relatos" (p. 14). Por tanto, en el PEP existe un interés en anclar la estética en la formación del futuro profesional. La inclusión de categorías como percepción, sensibilidad, creación y composición imprime un carácter artístico al programa académico en mención. Aquí lo artístico es antonomasia de lo estético. La "Prospectiva del objeto de estudio" formulada en el PEP así lo confirma:

[Desde la estética], la mirada se dirige al arte en cuanto este ofrece las posibilidades de revertir órdenes y crear múltiples "realidades". Pero, no es el arte de las minorías ilustradas, es el que ha 
descendido de los pedestales para incorporarse a lo más anodino, al discurrir de los hombres comunes y corrientes que no solo lo aprecian, sino que además lo crean desde sus prácticas cotidianas (estética de lo prosaico) (p.19).

El estudio de la estética pertenece a la Unidad de Organización Curricular, $\mathrm{UOC}^{8}$, denominada Expresión Estética y constituida por los cursos de Historia del Arte, Historia del Cine I, Historia del Cine II, Apreciación Musical, Introducción a la Literatura, Literatura Colombiana, Literatura Latinoamericana y Literatura Contemporánea. El problema de formación $n^{9}$ de esta UOC se establece con una pregunta: “¿Cómo desarrollar la facultad estética del estudiante de comunicación y lenguajes audiovisuales?" (p. 84), y, en consecuencia, el propósito de formación resultante es "desarrollar la facultad estética a partir del encuentro del estudiante con las artes plásticas, la música y la literatura" (ibíd.). ¿Cómo lo hacen?

Tomemos, por ejemplo, el microcurrículo de Historia del Arte. El objeto de estudio es el arte desde una perspectiva histórica en la plástica (p. 1), y el problema en el que se suscribe el curso está enunciado así: "Cuáles son los elementos conceptuales, técnicos, estéticos y socioculturales que caracterizan el arte en las diferentes épocas de la historia del arte en Occidente" (p. 1). En concordancia con lo anterior, la asignatura tiene como objetivo:

Comprender los elementos conceptuales, técnicos y los valores estéticos que han contribuido a la construcción y la valoración de obras de arte en un contexto histórico como una contribución a los procesos de conocimiento y conservación de la identidad y el patrimonio inmaterial nacional (p. 2).

A la par, y por medio de un método inductivo-deductivohermenéutico (p. 2), el curso busca desarrollar las competencias estética y argumentativa. Mientras, el contenido temático del microcurrículo es un recorrido historiográfico por épocas, teorías, artistas, y vanguardias del arte occidental; aspecto este

8 Este concepto recoge el conjunto de cursos subordinados a un mismo problema y propósito de formación que permiten tipificar cada grupo de asignaturas, a saber: conocimientos generales, conocimientos comunes, conocimientos específicos, líneas de énfasis, libre elección y trabajo de grado. La UOC expresión estética pertenece a conocimientos específicos.

9 El problema de formación atiende a una ausencia en el estudiante que pretende ser subsanada mediante el conjunto de asignaturas de la UOC. 
sostenido por una bibliografía en la cual aparecen títulos como Teoría y metodología de la historia del arte (J. Fernández), Tres miradas sobre el arte (R. Argullol), El sentido del gusto (C. Korsmeyer) y Punto y línea sobre el plano (V. Kandinsky), (p. 5).

En Historia del Cine I, las características son similares. Allí el objeto de estudio es el cine. Su objetivo es desarrollar las competencias argumentativa y estética. El método corresponde al histórico-hermenéutico y se incluyen los conceptos de tecnología, arte, ciencia, estudio, escuela, movimiento, género, autor, preproducción, producción, posproducción, distribución, exhibición, Hollywood, realismo, formalismo, neorrealismo, surrealismo y expresionismo (pp. 1-2). El contenido temático gira en torno a renombrados directores de cine, épocas y tendencias, acompañado por una extensa bibliografía cuya pretensión es instruir al estudiante alrededor de teóricas fílmicas. Textos como Hacia una teoría del montaje (S. M. Eisenstein), La narración en el cine de ficción (D. Bordwell), Textos y manifiestos del cine: Estética, escuelas, movimientos, disciplinas, innovaciones (J. Romaguera) (p. 6) hacen parte de la bibliografía.

En los cursos de literatura el panorama no varía. En cierta medida porque la UOC ejerce control sobre los métodos, los contenidos, las bibliografías y, como lo anotaremos más adelante, los proyectos de aula. En el microcurrículo de Introducción a la Literatura, el ob- jeto de estudio se define como "el fenómeno literario desde las perspectivas propias de la producción y recepción, y su incidencia en el ámbito de los lenguajes audiovisuales (cine, televisión, vídeo)" (p. 1). Entre tanto, el objetivo es identificar los elementos que determinan la producción literaria como expresión artística y estética, reconociendo las características propias del lenguaje en la poesía, la novela, el cuento, el teatro y el ensayo, para establecer conexiones significativas entre la narrativa literaria y la narrativa audiovisual (p. 2). Aquí -como en los otros microcurrículos- la literatura es referida, primordialmente, al manejo del lenguaje. En el caso de Literatura Contemporánea, los contenidos están encaminados a establecer relaciones entre la literatura y ciertos temas, a saber: literatura: modernidad y contemporaneidad; literatura y ciudad; desasosiego y extrañamiento en la literatura; amor y erotismo en la literatura, y literatura y fantasía. Aunque hay un intento por relacionar la literatura con otros temas de la vida, el abordaje se hace en función del mismo texto. Se trata de mirar cómo dichos temas aparecen reflejados en la obra literaria, pero no más. El soporte bibliográfico se concentra en tratados teóricos que redundan en las particularidades del texto literario. Ejemplo de ello es Teoría de la narrativa (B. Mieke), El análisis literario ( $\mathrm{R}$. Castagnino), Historia de la literatura universal (J. Ferrer) y Crítica a la modernidad (A. Touraine) (p. 5). En este 
mismo sentido se pueden incluir los microcurrículos de Literatura Latinoamericana y Literatura Colombiana. Se percibe, sobre todo, una preocupación por proporcionar al estudiante un contenido historiográfico de la literatura, al tiempo que se señalan, como base de estudio del texto, las teorías canónicas sobre el objeto artístico.

De otra parte, el proyecto de aula es generalizado para la UOC. Desde el título, Escritura creativa, hay un interés por el lenguaje literario. De nuevo, se considera el texto como un asunto exclusivo del lenguaje, en cuanto objeto de arte. El producto final del proyecto de aula se circunscribe en lo artístico, dado que al estudiante se le exige la creación de un relato.

En este orden de ideas todo parece indicar que en la academia la comprensión del texto solo puede hacerse mediante procedimientos que den cuenta de un rigorismo adecuado a teorías lingüísticas, semánticas, semióticas o filosóficas, erigidas en el soporte de lo que Eagleton (1994) denomina la institución-académica-literaria ${ }^{10}$. Se trata de un abordaje institucionalizado (profesional) de la literatura con escasas referencias al mundo de la vida cotidiana. ¿Para qué se estudia literatura en la universidad? Para descifrar los intríngulis de sus formas y estructuras, sería la respuesta desde los íconos comparados y analizados. ¿Pero acaso no persigue el desarrollo de la competencia estética? Entonces, ¿qué entienden por estética los profesores, los estudiantes y la institución? Con base en el PEP, el PEI y los microcurrículos, lo estético correspondería a un cúmulo de conocimientos sobre lingüística, semiótica, semántica, filosofía, hermenéutica, narratología, estructuralismo, formalismo y estética de la recepción, aplicados a novelas, cuentos y poemas.

\section{Los enigmas": ¿la literatura sólo incumbe al lenguaje?}

Sin lugar a dudas, el anterior análisis de los íconos (PEP, PEI, microcurrículos) conduce a preguntarse por las influencias del estudio de la literatura en la institución universitaria. Creemos que cada docente o institución lleva al aula de clase una concepción sobre el qué y el cómo estudiar la literatura. Esas influencias podrían estar determinadas por los bagajes académicos de los profesores y por las intenciones de un programa académico en particular. En am-

10 El autor no habla de la literatura en general, sino que la circunscribe, de manera específica, a la práctica de la enseñanza y del aprendizaje de los textos literarios en las instituciones universitarias. A eso se refiere cuando acuña el término institución-académica-literaria

11 El enigma es aquello que no alcanza a comprenderse o que difícilmente puede entenderse o interpretarse. En palabras de González (2012b), "nos percatamos de lo que ha sucedido, pero en eso sucedido algo está encubierto, oculto; algo se ve y otro algo no se ve... (p. 6). 
bos casos (profesores y programa), podría inferirse una correspondencia con las tendencias dominantes en los estudios literarios. Es decir, el docente, al ser formado por una institución que sigue lo canónico en la disciplina de estudio (la literatura, para nuestro caso), reflejaría en el aula los presupuestos desde los que fue educado profesionalmente. Y, de modo similar, la institución, al ser parte del, llamémoslo, statu quo en la educación superior colombiana, también se acogería a los principios dominantes de la formación de profesionales en el contexto propio sociocultural. La decisión por seguir lo dominantemente establecido tiene, por otra parte, sus pretensiones de responder a exigencias de movilidad estudiantil, internacionalización y estandarización de los títulos y programas ofrecidos, tal como lo señala el PEI de la Universidad de Medellín:

La Universidad de Medellín propende a currículos internacionalizados, en coherencia con las tendencias, métodos $y$ avances mundiales; promueve la movilidad de docentes y estudiantes. Contribuye a la que comunidad académica desarrolle competencias en lenguas extranjeras; se enriquezca de otras culturas y visiones... (p. 28).

Para cumplir con estas expectativas, la institución debe estar en consonancia con las demás univer- sidades del país y del mundo. Pretende que los cursos de literatura (o de cualquier otra materia) estudiados en la Universidad de Medellín sean homologables en universidades nacionales y extranjeras. Esta decisión, aunque de carácter administrativo y materializado como fundamento para la construcción del programa y su malla curricular, funciona como dispositivo desde el cual el estudio de una disciplina debe ser instalado en los límites teóricos, metodológicos, conceptuales y epistémicos dominantes. De ahí la pregunta que guía este enigma: ¿Cuáles son las influencias en el estudio de la literatura en la Universidad? Es decir, ¿a qué teorías o presupuestos de lo estético y, por consiguiente, de lo literario se acoge la institución? Porque, en efecto, el estudio de la literatura se ha trazado sobre ópticas establecidas con base en teorías ya mencionadas, pero existen otras visiones posibles ${ }^{12}$ sistemáticamente ausentes en la universidad. Digamos que si los docentes replican en el aula las visiones aprehendidas en su formación disciplinar y si la Universidad de Medellín (o cualquier otra institución) integra el statu quo de la educación superior, el escenario resultante es aquel en el que se resguarda la tradición académica; esto es, la aceptación y promoción de las tendencias canónicas en los asuntos referidos a los estudios de educación superior. Dentro de

12 Sobre los conceptos de establecido y posible leer Bruner (2003). Dichos conceptos son también asimilados como lo instituido y lo instituyente o lo canónico y lo posible. 
ese marco, los estudios literarios siguen el camino de teorías tradicionales, que hacen preguntarnos -a modo de enigma- si la literatura es un fenómeno que solo incumbe al lenguaje.

A partir del hecho sorprendente se manifiesta nuestra inquietud por las conexiones entre la literatura y la vida cotidiana en su dimensión estética. Es claro que una perspectiva del estudio de la literatura en relación con la estética cotidiana ${ }^{13}$ no aparece explícitamente referida en ninguno de los microcurrículos analizados. En ellos se intenta tímidamente conectar lo literario con temas de la vida, pero solo en función de comprender el mismo texto. Esa intención corre una suerte de bumerán, pues si bien la literatura se arroja al mundo de lo cotidiano, esta -obligatoriamente- regresa a sí misma en la búsqueda de una lectura, comprensión, sentido o interpretación del mismo texto. Lo anterior suscita esta inquietud enigmática: ¿cómo se justifica la ausencia de la vida cotidiana -en su dimensión estética- en el estudio de la literatura en la institución universitaria? La respuesta se cruza con la insinuada a la pregunta del enigma anterior: se trataría de seguir las tendencias de estudio canónicas y de asegurar un lugar en el statu quo de la educación superior. Pues incluir una perspectiva de estudio sobre la base de la vida cotidiana y su dimensión estética implicaría una opción posible y alterna a los estudios literarios dominantes, lo cual significaría un distanciamiento de la estandarización nacional e internacional de los microcurrículos y los planes de estudio, y en consecuencia la imposibilidad de homologar en esos ámbitos (nacional e internacional) las asignaturas cursadas en la Universidad de Medellín. Pero sobre todo obligaría a asumir una perspectiva que rebase el lenguaje como componente fundamental (o exclusivo) del texto literario, y proyectaría el estudio literario al mundo de la vida; no con el efecto bumerán del cual hablamos arriba, sino con el interés de irradiar la cotidianidad de un modo estético.

\section{Los indicios:" ¿por qué la literatura no resuena en el mundo de la vida?}

En este recorrido hacia la pregunta de la hipótesis abductiva se expresa nuestra sorpresa de que el estudio académico de la literatura deje por fuera su relación con la vida cotidiana (hecho

13 La estética cotidiana es una subdisciplina en las teorías estéticas contemporáneas que intenta ubicar lo estético en la cotidianidad y no en el arte. Ver Estética cotidiana y los juegos de la cultura. Prosaica (2006)

14 Un indicio es un "signo que se refiere al objeto que denota en virtud de que es realmente afectado por ese objeto" (Peirce, 1987, p. 250). 
sorprendente); hemos comparado y analizado unos iconos (PEI, PEP y microcurrículos) en los que la visión de lo estético y lo literario no traspasa los límites del lenguaje, y -a manera de enigmas- nos hemos preguntado por las influencias en el estudio de la literatura en la universidad y si la literatura es un fenómeno que incumbe solo al lenguaje. Los anteriores estadios nos abren, ahora, el camino a los indicios, a saber: lo estético se asimila como arte y la literatura es ante todo un asunto del lenguaje.

En cuanto al primer indicio encontramos que el PEI, el PEP y los microcurrículos -repetimos- privilegian lo canónico y el statu quo en lo referente al estudio de la literatura. Prueba de ello es el apego a teorías en las que lo estético es por antonomasia lo artístico. Rastros de este índex son las bibliografías de los microcurrículos revisados. En ellas las referencias se emparentan con la estética filosófica, la estética de la recepción, la narratología y las vanguardias preocupadas por el carácter artístico del texto literario. Algo parecido sucede con el segundo indicio: lo que importa a la institución-académica-literaria es descifrar las condiciones implícitas y explícitas del texto como fenómeno del lenguaje. El significado y el sentido del texto se encontrarían indagando -en exclusiva- por las peculiaridades del lenguaje. Se reafirma lo expresado en páginas anteriores: la dimensión de la estética se aísla de la sensibilidad (emociones, sensaciones, sentimientos, placer, etc.), para dar paso a los conocimientos racionalistas. La preocupación fundamental es el saber, no el sentir.

\section{Las sospechas's: ¿es posible el encuentro entre literatura y estética cotidiana?}

Ante este panorama, nuestro interés ha estado en buscar un intersticio entre la dimensión estética de la cotidianidad (estética cotidiana) y la literatura. Si la literatura se nutre de la vida, ¿por qué, en su estudio, no fluye hacia la vida para irradiarla en su modo estético? El escritor -sin lugar a dudas- toma sus experiencias de la vida diaria y las transforma en cuestiones que parecen incumbirnos a todos:

[Los escritores son] unos seres humanos que han tenido la capacidad de pasar la prueba de entrar en contacto consigo mismos, de reconocer las heridas secretas y explorarlas con paciencia hasta logar que los dolores y las nostalgias, los sueños y la melancolía, toman forma en personajes $y$ situaciones que les dan goce a los lectores a través de la palabra... (Bonilla, 2012).

\footnotetext{
5 La sospecha, en palabras de González (2012b), "supone una selección, un camino donde se debe decidir el rumbo de los significados, es la elección de una pregunta" que, citando a Gadamer, "permite siempre ver las posibilidades que quedan en suspenso" (p. 8).
} 
Ciertamente, en la creación literaria la cotidianidad es irresistiblemente penetrante. Pero una vez materializada (la cotidianidad) por el lenguaje en el texto, podría retornar a la vida irradiándola estéticamente. No bastaría con recurrir a la cotidianidad para explicar su aprehensión mimética por parte del arte literario, ni mucho menos para dar cuenta del carácter artístico del texto. La intensión sería otra: que la cotidianidad se perciba estéticamente desde el intersticio con la literatura. ¿Es posible concebir una estética cotidiana a partir la literatura? Esta es nuestra sospecha.

Como vemos, no se aboga por la disyunción literatura-vida cotidiana o arte-vida cotidiana. Emerge la sospecha de que es posible una suerte de síntesis entre los escenarios del arte y la vida. De algún modo ciertas vanguardias artísticas han encontrado confluencias entre arte y cotidianidad. Según Frías (2011), "The everyday aesthetics is incorporated in art through pieces in which activities, situations or banal images are brought up..." (p. 441). La idea de que la estética cotidiana puede incorporarse al arte en ciertas actividades, situaciones o imágenes se ilustra en el artículo de Frías (2011) con el artista relaciona/16, Rirkrit Tiravanija, quien en 1992 preparó una comida para una audiencia en una galería de arte de Nueva York. En el acto, los asistentes entraron en relación con el artista y participaron del performance ${ }^{17}$. Lo importante para artistas relacionales como Tiravanija es llevar la cotidianidad al ámbito del arte o viceversa (ibíd.).

Lo anterior -al igual que el dadaísmo ${ }^{18}$, el situacionismo ${ }^{19} \mathrm{y}$ otras vanguardias artísticas- es una señal inequívoca de la existencia de perspectivas contrarias a las convenciones dominantes que rigen el mundo del arte, enmarcadas por la objetualidad, la razón positivista y la exclusión del espectador. De ahí que interactuar sea casi una exigencia en algunas tendencias del

16 El artista relacional concentra su trabajo en el marco de las relaciones y su contexto social. Para ampliar el tema, ver Bourriaud, N. (2006). Estética relacional. Argentina: Adriana Hidalgo.

17 Es una acción artística que incluye tiempo, espacio, el cuerpo del artista y la relación de este con el cuerpo. Para la ampliación de la temática, consultar Howell, A. (2000). The Analysis of Performance Art. Ámsterdam, Holanda: Harwood Academic.

18 El dadaísmo fue un movimiento artístico surgido hacia 1916 y que se caracterizó por su inclinación constante, entre otras cosas, hacia la negación. Ver Dietmar, E. et. ál. (2004) Dadaísmo. Hong Kong: Taschen,.

19 El situacionismo consistió en un movimiento de carácter político y artístico cuyo planteamiento central era la creación de situaciones con propósitos de generar cambios en la vida cotidiana (emancipación). Raoul Vaneigem (La revolución de la vida cotidiana 1967) y Guy Debord (La sociedad del espectáculo, 1967) se encuentran entre los autores representativos de dicho movimiento. 
arte contemporáneo, en las que se incluyen todos los sentidos y diferentes medios para garantizar la relación entre la obra y el espectador (p. 442).

Ahora bien, la sospecha aquí enunciada no se dirige a la creación de obras de arte con las circunstancias, objetos y situaciones de la vida cotidiana. La indagación es sobre la posibilidad de concebir una estética cotidiana (no una obra de arte) a partir de la literatura. Si tenemos en cuenta que los relatos son modelos para volver a describir el mundo (Ricoeur, 2004) y si "la ficción crea realidades tan convincentes que dan forma a nuestra experiencia" (Bruner, 2003, p. 10), entonces creemos que esta suspicacia podría ir bien encaminada.

\section{La conjetura:20 ¿qué podemos predecir de la relación literatura y estética cotidiana?}

Dicho lo anterior, se propone una variante en las perspectivas de la institución-académica-literaria. Esta consistiría en descentrar los estudios racionalistas que ubican al texto como núcleo cerrado (autorreferencial) de la comprensión, la interpretación y el sentido. El propósito, ahora, sería proyectar el texto al mundo de la vida como posibilidad de irradiación estética de la cotidianidad. En consecuencia, la literatura

20 La conjetura, en cuanto juicio allegado a partir de los indicios, "permite efectuar una predicción" (González, 2012b, p. 8). potenciaría la estética cotidiana; esa es la conjetura, en ella creemos. La creencia en la posibilidad de que la literatura potencie la estética cotidiana está arraigada en la idea de que el texto literario tiene su germen en la vida cotidiana, tal como lo señalábamos con Bonilla (2012) en el apartado anterior. Entonces, esa cotidianidad virtualizada por el lenguaje en el texto podría proyectarse en una estética cotidiana. No sería la cotidianidad en bruto, surgiendo a borbotones, en su facticidad incierta y aleatoria, sino una cotidianidad atravesada por la mirada estética que la transforma (le da forma) en una estética cotidiana. Esta opción obliga a dejar atrás (o poner en un segundo plano), teorías -que en pos de la erudición- explican -con supuesto rigor científico- el objeto-arte a fin de producir conocimientos. Ante este afán de erudición, poetas como Milosz (citado en Bruner, 2004) ya han expresado su desconfianza:

Se han escrito muchos libros eruditos sobre poesía, y tienen, por lo menos en los países de Occidente, más lectores que la poesía misma. No se trata de una buena señal, aun cuando pueda explicarse por la inteligencia de sus autores y por su fervor para asimilar disciplinas científicas que hoy gozan del respecto universal. El poeta que quisiera competir con esas 
montañas de erudición tendría que fingir que posee más conocimiento de sí mismo del que se les permite tener a los poetas (p. 15).

Pues bien, la búsqueda no es la erudición. La mirada está puesta en el texto literario $y$, sobre todo, en las posibilidades de potenciar una estética cotidiana.

\section{La hipótesis abductiva21: ¿cómo la literatura fundamentaría la estética cotidiana como principio para la educación superior?}

En este orden de ideas, llegamos a la formulación de la hipótesis abductiva. En el marco de este proyecto de investigación, nos propondremos -a futuro- la creación de algo, a fin de contribuir a las disciplinas en las cuales nos inscribimos: la estética cotidiana y la literatura en la educación superior. En el entretejido construido a través del hecho sorprendente, los íconos, los enigmas, los indicios, las sospechas y las conjeturas, llegamos a la pregunta de la hipótesis abductiva: ¿cómo la literatura fundamentaría la estética cotidiana como principio para la educación superior?

La cosa que se intenta crear es un principio aplicable a la educación superior. Dicho principio puede configurarse con base en una fundamentación de la estética cotidiana a partir de la literatura, teniendo presente que el texto literario potenciaría la mirada estética sobre la cotidianidad. La potencia, entendida como la potencialidad que reside en una cosa de pasar a otro estado (Ferrater y Terricabras, 2001) ${ }^{22}$, concuerda con nuestra visión de lo literario. Dentro de este contexto, se ha de entender por principio la base o razón fundamental para discurrir sobre el estudio de la literatura; esto aplicado al programa de Comunicación y Lenguajes Audiovisuales de la Universidad de Medellín, con la posibilidad de replicarlo en toda la universidad (y en otras). En tal sentido, el principio adquiriría un carácter general, similar a lo que sucede en muchas universidades en relación con las competencias en lengua extranjera, comprensión lectora, razonamiento lógico y expresión escrita. Los cursos que desarrollan dichas competencia son de obligatorio estudio para todos los estudiantes. Asimismo, la literatura podría ser un

"La hipótesis abductiva es el preámbulo a un acto de creación; con ella se da inicio a todo proceso de conocer, mediante el lenguaje, compuesto de símbolos" (ibíd.)

22 Esta definición recoge la visión aristotélica de potencia. 
curso general orientado al desarrollo de la competencia de la estética cotidiana.

El cómo hacerlo es lo que tendremos que indagar de aquí en adelante, porque el propósito de este artículo era mostrar el recorrido hacia la hipótesis abductiva.

\section{Referencias}

Barbery, M. (2010). La elegancia del erizo. Bogotá: Planeta.

Bonilla, M. E. (2012). El encanto de los escritores. El Espectador. Recuperado de http:// www.elespectador.com/impreso/opinion/columna323635-el-encanto-de-los-escritores

Bourdieu, P. (2005). Las reglas del arte: génesis y estructura del campo literario. Barcelona: Anagrama.

Bruner, J. (2003). Making stories: law, literature, life. Cambridge, M.A: Harvard University Press.

Bruner, J. (2004). Realidad mental y mundos posibles. Barcelona, España: Gedisa.

Eagleton, T. (1994). Una introducción a la teoría literaria. Bogotá: Fondo de Cultura Económica.

Espejo, R. (2008). Peirce, la abducción y la investigación científica. Revista Observaciones filosóficas, 6. Recuperado de http:// www.observacionesfilosoficas. net/peircelaabduccion.html

Ferrater M. J. \& Terricabras, J. M. (2001). Diccionario de filosofía. Barcelona: Ariel.
Frías, G. (2011). Everyday Aesthetics in Contemporary Art. Rupkatha Journal on Interdisciplinary Studies in Humanities, (3)3, pp. 440-447. Recuperado de http://rupkatha.com/V3/n3/09_ Everyday_Aesthetics_in_Contemporary_Art.pdf

González, A. E. (2012b). Entre la abducción y la hermenéutica o sobre un hipótesis que generará un cosa por crear. [Manuscrito presentado el 19 de abril] Seminario Complementario. Universidad de Antioquia.

Nussbaum, M. (1997). Justicia poética. Barcelona: Andrés Bello.

Mandoki, K. (2006). Estética cotidiana y juegos de la cultura. Prosaica I. México D.F.: Siglo Veintiuno.

Peirce, C. S. (1970). Deducción, inducción e hipótesis. Buenos Aires: Aguilar.

Peirce, C. S. (1974). La ciencia de la semiótica. Buenos Aires: Nueva Visión.

Peirce. C. S. (1987). Obra lógicosemiótica. Madrid: Taurus.

Peirce, C.S. (1988). El hombre, un signo. Barcelona: Crítica.

Ricoeur, P. (2006). Tiempo y narración I. México, D.F.: Siglo XXI.

Todorov, T. (2009). La literatura en peligro. Barcelona: Círculo de Lectores.

Todorov, T. (1970). Teoría de la literatura de los formalistas rusos. Buenos Aires: Signos.

Vargas Llosa, M. (2012). La civilización del espectáculo. Bogotá: Alfaguara. 
Universidad de Medellín. (2010). Proyecto Educativo Institucional PEI. Recuperado de http://www.udem.edu.co/NR/ rdonlyres/4F87F262-73B5-436B-A527-84B4D99C4B21/0/decreto03de2010.pdf

Universidad de Medellín. (2010). Proyecto Educativo del Programa Comunicación y Lenguajes Audiovisuales, PEP. Recuperado de http://www.udem.edu.co/UDEM/Programas/Pregrados/ComunLenguajesAud/

Universidad de Medellín. (2012). Microcurrículo Historia del Arte. Facultad de Comunicación. Medellín, Colombia.

Universidad de Medellín. (2012). Microcurrículo Historia del Arte. Facultad de Comunicación. Medellín, Colombia.

Universidad de Medellín. (2012). Microcurrículo Historia del Cine I. Facultad de Comunicación. Medellín, Colombia.

Universidad de Medellín. (2012). Microcurrículo Introducción a la Literatura. Facultad de Comunicación. Medellín, Colombia.

Universidad de Medellín. (2012). Microcurrículo Literatura Contemporánea. Facultad de Comunicación. Medellín, Colombia. Universidad de Medellín. (2012). Microcurrículo Literatura Colombiana. Facultad de Comunicación. Medellín, Colombia.

Universidad de Medellín. (2012). Microcurrículo Literatura Latinoamericana. Facultad de Comunicación. Medellín, Colombia.

Universidad de Medellín. (2012). Proyecto de aula UOC Expresión Estética. Facultad de Comunicación. Medellín, Colombia. 